CASE REPORT

\title{
Pathogenic Sarcina in urine
}

\author{
Karthik Bommannan, ${ }^{1}$ Balan Louis Gaspar, ${ }^{2}$ Man Updesh Singh Sachdeva ${ }^{1}$
}

${ }^{1}$ Department of Hematology, Post Graduate Institute of Medical Education and Research (PGIMER), Chandigarh, India ${ }^{2}$ Department of Histopathology, Post Graduate Institute of Medical Education and Research (PGIMER),

Chandigarh, India

\section{Correspondence to}

Dr Man Updesh Singh

Sachdeva, drmanupdeshpgi@ yahoo.co.in

Accepted 23 September 2016

\section{SUMMARY}

Sarcina is a Gram-positive anaerobic coccus that has been consistently reported in the upper gastrointestinal tract biopsies of patients with evidence of gastric stasis. The pathogenic role of Sarcina in humans is not entirely known. We describe an infant who was surgically treated for posterior urethral valve and the urine showed pathogenic Sarcina.

\section{BACKGROUND}

Sarcina is a Gram-positive anaerobic coccus that is well known for its association with lethal 'abomasal bloat' in the livestock. In recent years, Sarcina has been consistently reported in the upper gastrointestinal tract (UGIT) biopsies of patients with evidence of gastric stasis. ${ }^{1}$ The pathogenic role of Sarcina in human beings is not clear. Other than the gastrointestinal tract, a Sarcina has been documented in a case of lung infarction. ${ }^{2}$ We describe an infant who was surgically treated for posterior urethral valve with bilateral grade $\mathrm{V}$ vesicoureteric reflux and the urine showed pathogenic Sarcina.

\section{CASE PRESENTATION}

A male infant aged 10 months with posterior urethral valve and bilateral grade $\mathrm{V}$ vesicoureteric reflux underwent transurethral fulguration. The postoperative period was uneventful. After 5 months, he developed stricture of the membranous urethra and was treated by urethral dilation. The routine urine specimen was turbid. Subsequently, under aseptic precautions, a suprapubic aspiration of urine sample was collected. Wet-mount preparation of the suprapubic urine sample showed plenty of pus cells. In addition, organisms with morphology consistent with that of Sarcina were seen (figure 1A). May-Grünwald Giemsa staining was performed on the air-dried urine smears (figure 1B, C). The smears revealed tetrad and octet arrangement of Gram-positive cocci characteristic of Sarcina (figure 1D). A few were also seen within the cytoplasm of the phagocytes. However, the urine cultures were sterile.

\section{TREATMENT}

The child received a combination of ciprofloxacin and metronidazole for 2 weeks and the repeat urine samples were negative for Sarcina.

\section{OUTCOME AND FOLLOW-UP}

Since the facilities for sequencing of Sarcina genome were not available in our centre, the urine samples were not further subjected to molecular genetic studies for confirmation.
To cite: Bommannan $\mathrm{K}$, Gaspar BL, Sachdeva MUS BMJ Case Rep Published online: [please include Day Month Year] doi:10.1136/ bcr-2016-216991

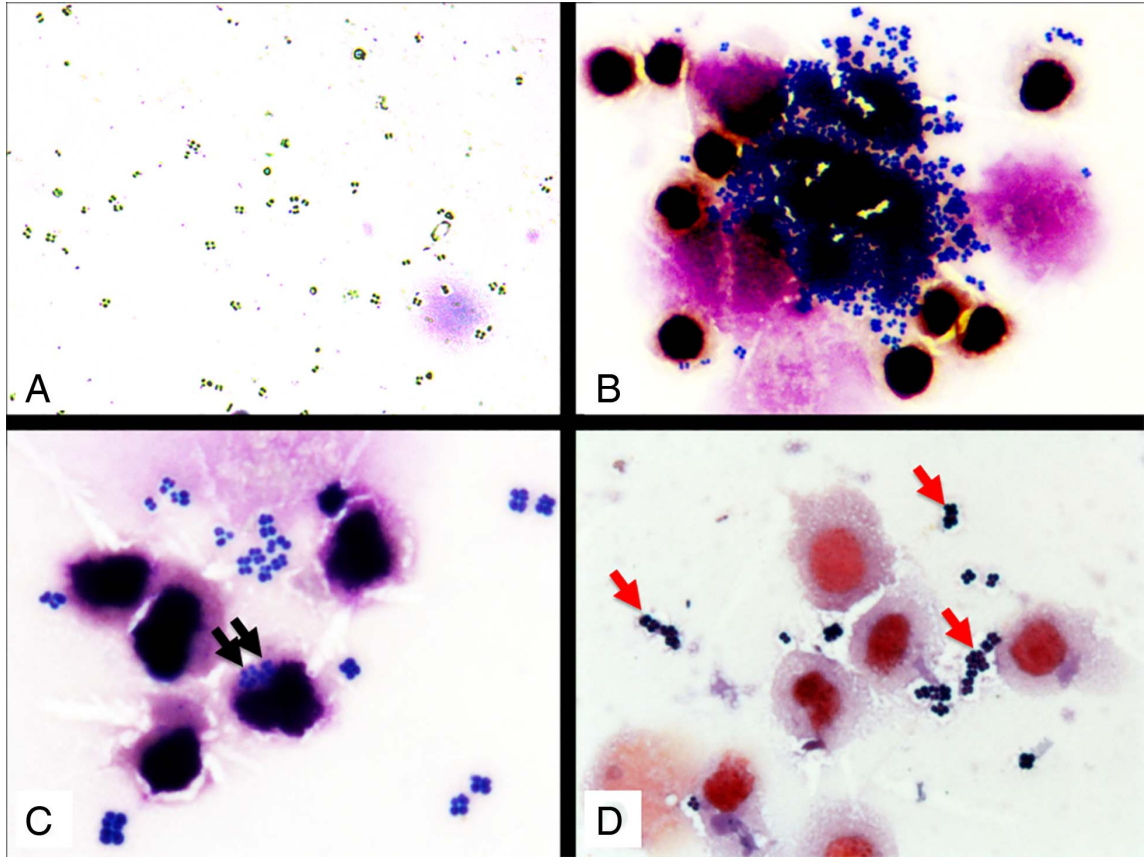

Figure 1 Sarcina in urine. (A) Unstained wet-mount urine preparation showing plenty of Sarcina; (B) air-dried urine smears stained with May-Grünwald Giemsa showing clusters of Sarcina. (C) Black arrow shows phagocytosed Sarcina; (D) Gram-positive Sarcina (red arrows). 


\section{DISCUSSION}

Sarcina was first documented in 1842 by Goodsir. ${ }^{3}$ It is a Gram-positive, spore forming, obligate anaerobic coccus belonging to the Clostridiaceae family. ${ }^{4}$ The organism's peculiar arrangement in tetrads and octets is readily identified by light microscopy. ${ }^{5}$ There has been an exponential rise in the number of publications documenting Sarcina in the UGIT of human beings. ${ }^{1}$ Although Sarcina has a well-established role in the aetiopathogenesis of 'abomasal bloat' (a lethal disease of the livestock), its role as a human pathogen is not clear. ${ }^{6}$ Recent literature suggests that Sarcina does have a pathogenic role in human beings. ${ }^{7-10}$ Apart from UGIT, Sarcina has been identified in pulmonary gangrene and peripheral blood, but these patients also had comorbidities causing GI dysfunction. ${ }^{211}$ It is hypothesised that gastric stasis is a harbinger of Sarcinosis. ${ }^{1}$ Hence, the detection of Sarcina in gastric biopsies is a surrogate marker of stasis. Sarcina is a part of normal cutaneous and colonic microbiota. ${ }^{12}$ In the index case, there were no signs of fistulous communications between the urinary, gastrointestinal or cutaneous tracts. Moreover, demonstration of Sarcina in the suprapubic urine sample with aseptic precautions literally rules out contamination. This is corroborated by the presence of phagocytosed Sarcina which is a strong indicator of host response to the

\section{Learning points}

- The existing literature has focused Sarcina as an organism restricted to the gastrointestinal tract (GIT). Our report suggests that Sarcina is not restricted to the GIT alone.

- In the index case, posterior urethral valve and surgical interventions would have resulted in urine stasis with subsequent Sarcinosis. This phenomenon is similar to the gastric stasis hypothesis.

- Our case adds new insights into the existing knowledge with regard to the aetiopathogenic role of Sarcina and emphasises the fact that the infection is potentially treatable with appropriate antibiotics. pathogen. The prompt response to antibiotic treatment in turn supports the pathogenic role of Sarcina in the index case. Getting a sterile urine culture is not uncommon because Sarcina is a fastidious organism and requires special techniques for isolation. ${ }^{13}$

Contributors $\mathrm{KB}, \mathrm{BLG}$ and MUSS contributed equally in reporting and writing the paper.

Competing interests None declared.

Patient consent Obtained.

Provenance and peer review Not commissioned; externally peer reviewed.

\section{REFERENCES}

1 Gaspar BL. The significance of Sarcina in routine surgical pathology practice. APMIS 2016;124:436-43.

2 Chougule A, Muthu V, Bal A, et al. Pulmonary gangrene due to Rhizopus spp., Staphylococcus aureus, Klebsiella pneumoniae and probable Sarcina organisms. Mycopathologia 2015;180:131-6.

3 Ferrier D. The constant occurrence of Sarcina Ventriculi (Goodsir) in the blood of man and the lower animals: with remarks on the nature of Sarcinous vomiting. Br Med J 1872;1:98-9.

4 Lawson PA, Rainey FA. Proposal to restrict the genus Clostridium (Prazmowski) to Clostridium butyricum and related species. Int I Syst Evol Microbiol 2016;66:1009-16.

5 Sopha SC, Manejwala A, Boutros CN. Sarcina, a new threat in the bariatric era. Hum Pathol 2015;46:1405-7.

6 Marshall TS. Abomasal ulceration and tympany of calves. Vet Clin North Am Food Anim Pract 2009;25:209-20.

7 Lam-Himlin D, Tsiatis AC, Montgomery E, et al. Sarcina organisms in the gastrointestinal tract: a clinicopathologic and molecular study. Am J Surg Pathol 2011;35:1700.

8 Carrigan S, Grin A, Al-Haddad S, et al. Emphysematous oesophagitis associated with Sarcina organisms in a patient receiving anti-inflammatory therapy. Histopathology 2015;67:270-2.

9 Laass MW, Pargac N, Fischer R, et al. Emphysematous gastritis caused by Sarcina ventriculi. Gastrointest Endosc 2010;72:1101-3.

10 Louis GB, Singh P, Vaiphei K. Sarcina infection. BMJ Case Rep 2014;2014:pii: bcr2013201185.

11 Tuuminen T, Suomala P, Vuorinen S. Sarcina ventriculi in blood: the first documented report since 1872. BMC Infect Dis 2013;13:169.

12 Canale-Parola E, Wolfe RS. Studies on Sarcina ventriculi. II. Nutrition. J Bacteriol 1960;79:860-2.

13 Goodwin S, Zeikus JG. Physiological adaptations of anaerobic bacteria to low pH: metabolic control of proton motive force in Sarcina ventriculi. J Bacteriol 1987:169:2150-7.

Copyright 2016 BMJ Publishing Group. All rights reserved. For permission to reuse any of this content visit

http://group.bmj.com/group/rights-licensing/permissions.

BMJ Case Report Fellows may re-use this article for personal use and teaching without any further permission.

Become a Fellow of BMJ Case Reports today and you can:

- Submit as many cases as you like

- Enjoy fast sympathetic peer review and rapid publication of accepted articles

- Access all the published articles

- Re-use any of the published material for personal use and teaching without further permission

For information on Institutional Fellowships contact consortiasales@bmjgroup.com

Visit casereports.bmj.com for more articles like this and to become a Fellow 